\title{
The Effect of an External Periodic Perturbation on a Burst Oscillation in a Simple Model for the Briggs-Rauscher Reaction
}

\author{
Kyoung-Ran Kim and Dong J. Lee* \\ Department of Chemistry, Pukyong National University, Pusan 608-737, Korea. "E-mail: dilee@pkniac.kr \\ Received Angust 22, 2008
}

$\Lambda$ external periodic perturbation's effect is numerically discussed, when it acts on burst oscillation in a model for the Briggs-Rauscher reaction in a continuous stirred tank reactor. The numerical results reveal that perturbation generates chaotic, mixed, multiple periodic and single oscillations.

Key Words : Burst oscillation, Supercritical Hopf bifurcation, Secondary Hopf bifurcation

\section{Introduction}

Considerable theoretical and experimental works have been performed on periodically perturbed chemical oscillators. ${ }^{1-4}$ These studies have demonstrated fascinating phenomena, such as quasi-periodic and chaotic responses of a driven system, entrainment of oscillatory systems, generation of new limit cycles by perturbation, phase transitions in extemally driven systems; chaos control, among others.

A simplified model for the Briggs-Rauscher (BR) reaction mechanism, which consists of four intermediates and seven steps, has been proposed. ${ }^{3}$ With the aid of this model, this study has obtained numerical results for nonlinear dynamic behaviors such as oscillations, limit cycle, bistability, and inverse regulation of the iodine concentration in a continuous stirred tank reactor (CSTR). A comparison of the numerical results with experiments ${ }^{6-9}$ and other previous models ${ }^{10-13}$ reveals that the current simplified model expresses nonlinear dynamic behaviors better than the previous models. Furthemore, we ${ }^{1+}$ have observed mixed mode oscillations with an incomplete Farey sequence, periodicchaotic (or nonperiodic) sequence, and various types of burst oscillations within the secondary Hopf bifurcation curves by controlling malonic acid's flow rate and input concentration.

This paper aims to demonstrate an extemal periodic perturbation's effect ${ }^{11}$ on a burst oscillation. The perturbation drives the burst oscillation to chaotic, mixed or simple oscillation, depending on the perturbation's intensity and frequency.

\section{Results and Discussions}

The simple model for the $\mathrm{BR}$ reaction mechanism is as follows ${ }^{3}$

$$
\begin{aligned}
& \begin{array}{c}
\mathrm{HOI}+\mathrm{I}^{-}+\mathrm{H}^{+} \underset{k_{l-1}}{\stackrel{k_{\mathrm{I}}}{\rightleftarrows}} \mathrm{I}_{2}+\mathrm{H}_{2} \mathrm{O} \quad k_{\mathrm{II}}=3 . \mathrm{I} \times 10^{12} \mathrm{M}^{-3_{5}-1} \\
k_{\mathrm{l}-1}=2.2 \mathrm{~s}^{-1}
\end{array} \\
& \mathrm{H}^{\prime}+\mathrm{HOIO}+\mathrm{I}^{-} \stackrel{k_{2}}{\longrightarrow} 2 \mathrm{HOI} \quad k_{2}=7.5 \times 10^{8} \mathrm{M}^{-2} \mathrm{~s}^{-1} \\
& 2 \mathrm{H}^{+}+\mathrm{IO}_{3}^{-}+\mathrm{I}^{-} \stackrel{k_{\mathrm{l} 3}}{\longrightarrow} \mathrm{HOIO}+\mathrm{HOI} \\
& k_{13}=1.4 \times 10^{3} \mathrm{M}^{-2} \mathrm{~s}^{-1}
\end{aligned}
$$

$$
\begin{aligned}
& 2 \mathrm{HOIO} \stackrel{k_{4}}{\longrightarrow} \mathrm{H}^{1}+\mathrm{IO}_{3}^{-}+\mathrm{HOI} \quad k_{4}=3.0 \times 10^{9} \mathrm{M}^{-1} \mathrm{~s}^{-1} \\
& \mathrm{H}^{1}+\mathrm{IO}_{3}^{-} \mathrm{HOIO} \stackrel{k_{55^{\prime}}}{\longrightarrow} 2 \mathrm{HOIO}+\frac{1}{2} \mathrm{O}_{2} \\
& k_{5}=2.6 \times 10^{5} \mathrm{M}^{-2}-1 \\
& k_{\mathrm{c} 5}=3.4942 \mathrm{M}^{-1} \mathrm{~s}^{-1} \\
& k_{\mathrm{DI}}=2.0 \times 10^{3} \mathrm{M}^{-1} \mathrm{~s}^{-1}(\mathrm{D} 1)
\end{aligned}
$$

The rate equations in a CSTR become the following:

$$
\begin{aligned}
& \frac{d X}{d t}=-k_{I 2} H X Y+k_{l 3} B H^{2} Y-2 k_{l 4} X^{2}+k_{l 5} B H X-k_{0} X \\
& \begin{aligned}
\frac{d Y}{d t}= & -k_{11} H Y W+k_{j-1} Z-k_{I 2} H X Y-k_{j 3} B H^{2} Y+k_{C 5} M A Z \\
& +k_{D 1} D W-k_{0} Y
\end{aligned} \\
& \frac{d Z}{d t}=k_{j 1} H I W-k_{i-1} Z-k_{C S} M A Z-k_{0} Z \\
& \begin{aligned}
\frac{d W}{d t}= & -k_{11} H Y W+k_{j-1} Z+2 k_{2} H X Y+k_{33} B H^{2} Y+k_{h} X^{2} \\
& -k_{D 1} D W-k_{0} Y
\end{aligned} \\
& \frac{d B}{d t}=-k_{r_{3}} B H^{2} Y+k_{74} X^{2}-k_{F} B H X-k_{0}\left(B-B_{0}\right)
\end{aligned}
$$

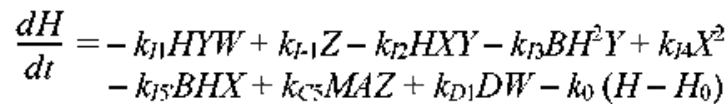

$$
\begin{aligned}
& \frac{d M A}{d t}=-k_{c} M A Z-k_{0}\left(M A-M A_{0}\right) \\
& \frac{d D}{d t}=-k_{D 1} D W-k_{0}\left(D-D_{0}\right)
\end{aligned}
$$

where $[\mathrm{HOIO}]=X,\left[\mathrm{I}^{-}\right]=Y,\left[\mathrm{I}_{2}\right]=Z,[\mathrm{HOI}]=W,\left[\mathrm{IO}_{3}^{-}\right]=B$, $\left[\mathrm{H}^{\prime}\right]=H,\left[\mathrm{CH}_{2}(\mathrm{COOH})_{2}\right]=M A$, and $\left[\mathrm{H}_{2} \mathrm{O}_{2}\right]=D$. In CSTR, the quantities $\left[\mathrm{C}_{\mathrm{i}}\right]_{0}$ refer to the inflow concentrations of the respective species $\mathrm{IO}_{3}{ }^{-}, \mathrm{H}^{\prime}, \mathrm{CH}_{3}(\mathrm{COOH})_{2}$, and $\mathrm{H}_{2} \mathrm{O}_{2}$. Meanwhile, $k_{0}$ refers to the flow rate. There are four intermediates in the present model, and these are HOIO, I$\mathrm{I}_{2}$ and $\mathrm{HOI}$.

At the condition $\left[\mathrm{H}^{\prime}\right]_{0}=0.057 \mathrm{M},\left[\mathrm{IO}_{3}{ }^{-}\right]_{0}=0.020 \mathrm{M}$, $\left[\mathrm{H}_{2} \mathrm{O}_{2}\right]_{0}=1.1 \mathrm{M}$ and $\left[\mathrm{CH}_{2}(\mathrm{COOH})_{2}\right]_{0}=0.070 \mathrm{M}$, the 


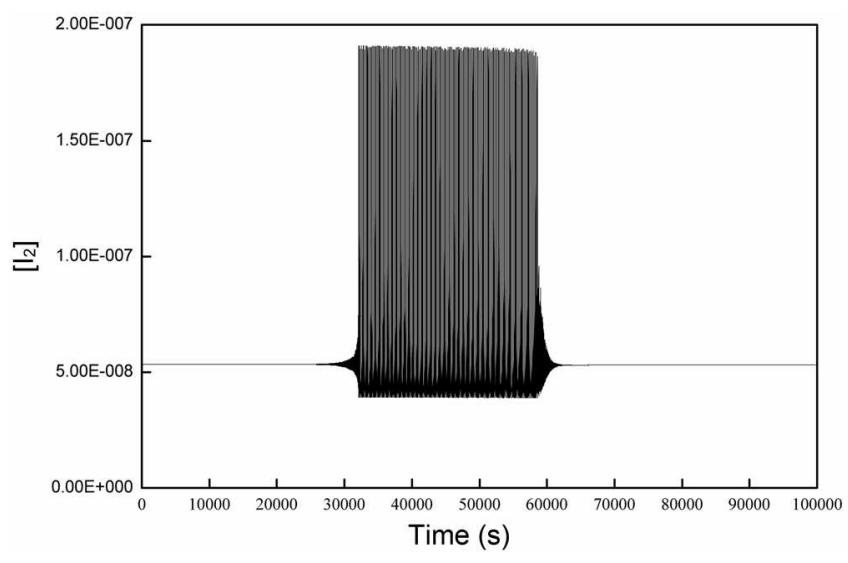

Figure 1. Burst oscillation without perturbation at the condition $\left[\mathrm{H}^{+}\right]_{0}=0.057 \mathrm{M},\left[\mathrm{IO}_{3}^{-}\right]_{0}=0.020 \mathrm{M},\left[\mathrm{H}_{2} \mathrm{O}_{2}\right]_{0}=1.1 \mathrm{M},=0.070 \mathrm{M}$, and $\mathrm{k}_{0}=5.9 \times 10^{-1} \mathrm{~s}^{-1}$.

secondary Hopf bifurcation exists between $k_{0}=5.86 \times 10^{-7}$ $\mathrm{s}^{-1}$ and $3.4 \times 10^{-5} \mathrm{~s}^{-1}$. A burst oscillation occurs at an oscillating state near the bifurcation point, as illustrated in Figure 1.
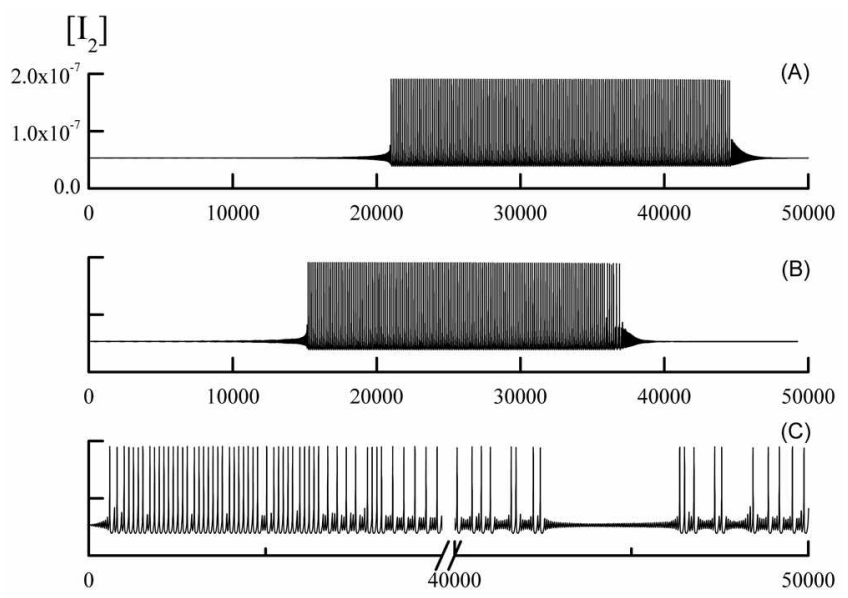

(D)

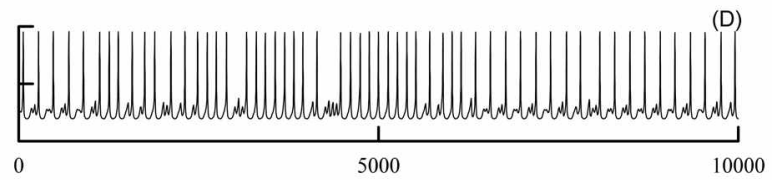

(E)
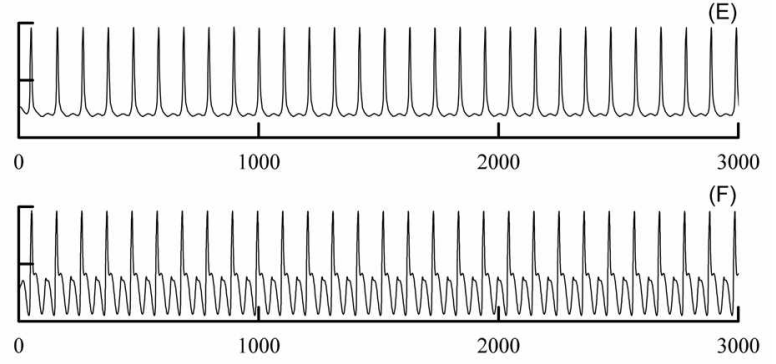

Time(s)

Figure 2. The effect of an external periodic perturbation with $\omega=$ $0.12 /$ s on the burst oscillation when the intensity, $\mathrm{I}(0)$ is $(\mathrm{A}) 1 \times 10^{-13}$ $\mathrm{M} / \mathrm{s}$; (B) $] \times 10^{-12} \mathrm{M} / \mathrm{s}$; (C) $\mid \times 10^{-11} \mathrm{M} / \mathrm{s}$; (D) $1 \times 10^{-10} \mathrm{M} / \mathrm{s}$; (E) $] \times$ $10^{-9} \mathrm{M} / \mathrm{s}$ and $(\mathrm{F}) 1 \times 10^{-8} \mathrm{M} / \mathrm{s}$. The other constants values are the same as those in Figure 1.
Let us consider the external periodic perturbation's effect on the burst oscillation. Assuming that for simplicity, an extenal perturbation, $I(t)$ is merely acted on the intermediate, $\mathrm{I}_{2}$ to observe various oscillations driven by the perturbation, the differential equation for $Z$ in Equation ( 1 ) is replaced by the following

$$
\frac{a Z}{d t}=k_{11} H I W-k_{j-1} Z-k_{r 5} M A Z-k_{0} Z+I(t),
$$

where $I(t)=l_{0} \sin (\omega t)$. The kinetic equations are numerically solved by using the CONTENT 1.5 program. ${ }^{15}$

Let us consider the case in which the value $\omega$ is close to the imaginary eigenvalue of Eq. (1), $\pm 0.127 / \mathrm{s}$, that is, $\omega=$ $0.120 / \mathrm{s}$. When $\mathrm{I}_{0}$ is $10^{-13} \mathrm{M} / \mathrm{s}$, perturbation has virtually no effect on the shape of oscillation. However, it tends to burst the oscillation earlier than expected (Figure $2 \mathrm{~A}$ ). As $\mathrm{I}_{0}$ is increased up to $10^{-12} \mathrm{M} / \mathrm{s}$, a transiently increasing beat oscillation appears due to the resonance between the intermediate and perturbation; burst oscillation occurs and the perturbation causes to appear a chaotic oscillation near the end of the burst oscillation (Figure $2 \mathrm{~B}$ ). When $\mathrm{I}_{0}$ is $10^{-11}$ $\mathrm{M} / \mathrm{s}$, a type of chaotic oscillation occurs, as illustrated in
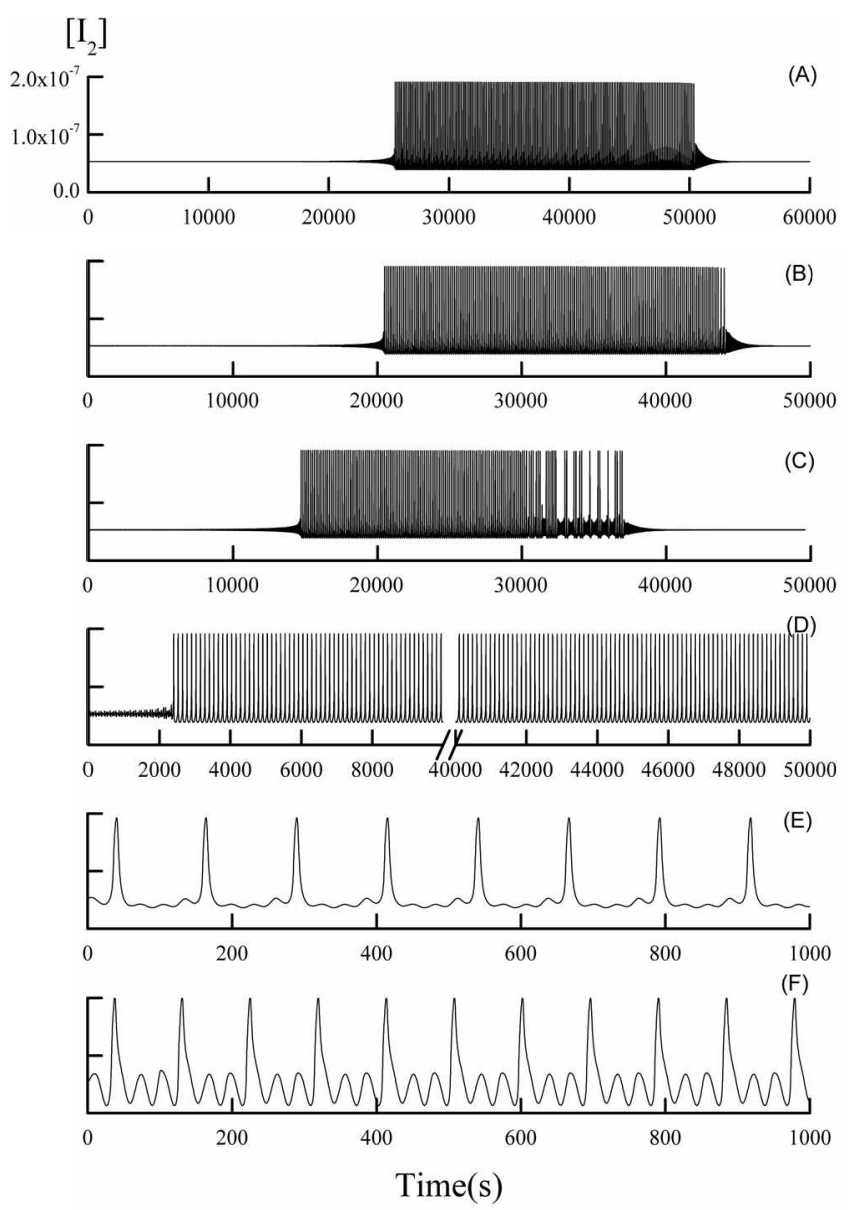

Figure 3. The effect of an external periodic perturbation with $\omega=$ $0.2 / \mathrm{s}$ on the burst oscillation when the intensity, $\mathrm{I}(0)$ is $(\Lambda) 1 \times 10^{-13}$ $\mathrm{M} / \mathrm{s}$; (B) $1 \times 10^{-12} \mathrm{M} / \mathrm{s}$; (C) $1 \times 10^{-11} \mathrm{M} / \mathrm{s}$; (D) $1 \times 10^{-10} \mathrm{M} / \mathrm{s}$; (E) $1 \times$ $10^{-9} \mathrm{M} / \mathrm{s}$ and $(\mathrm{F}) 1 \times 10^{-8} \mathrm{M} / \mathrm{s}$. The other constants' values are the sane as those in Figure 1. 
Figure $2 \mathrm{C}$. Increasing $\mathbf{I}_{0}$ further generates a different type of chaotic oscillation (Figure 2D). When intensity is reinforced, the chaotic oscillation transforms into a mixed oscillation with a large amplitude and small amplitudes, as illustrated in Figures $2 \mathrm{E}$ and $2 \mathrm{~F}$. This is due to the fact that the perturbation shifts the system into the region of new oscillations and couples with intemal oscillation.

There are cases wherein the frequency is far from the imaginary eigenvalue, that is, $\omega=0.200 / \mathrm{s}$. In the cases of $I_{0}$ $=10^{-13}$ and $10^{-12}$, the results are similar to those of $\omega=$ $0.120 / \mathrm{s}$, with the exception of two different points (see Figures $3 \mathrm{~A}$ and $3 \mathrm{~B}$ ). First, the burst oscillation of $\omega=0.120 /$ $\mathrm{s}$ occurs relatively earlier than that of $\omega=0.200 / \mathrm{s}$. Second, a transiently increasing beat oscillation is observed at $\omega=$ $0.120 / \mathrm{s}$ when $\mathrm{I}_{0}=10^{-12} \mathrm{M} / \mathrm{s}$. In addition, the perturbation of $\mathrm{I}_{0}=10^{-11}$ and $10^{-10} \mathrm{M} / \mathrm{s}$ results in chaotic oscillations, which is less complicated than that of $\omega=0.12 / \mathrm{s}$, as illustrated in Figures $3 \mathrm{C}$ and $3 \mathrm{D}$. As the intensity is intensified to a maximum of $10^{-9} \mathrm{M} / \mathrm{s}$, the oscillation is modified into a mixed oscillation, with a single large amplitude and three small amplitudes (Figure 3E).

\section{Conclusions}

Important results are summarized as follows:

(1) As the intensity is increased, the perturbation causes burst oscillations at a supereritical Hopf bifurcation state to be chaotic. This means that the perturbation shifts the state into one that is near the critical point between the super- critical Hopf bifurcation branch and secondary Hopf bifurcation branch. The further increasing intensity shifts the state into a new supercritical Hopf bifurcation states.

(2) The forced oscillation with the perturbation's frequency, which is closer to the system's imaginary part, is more complicated due to the resonance effect.

Acknowledgments. This work was supported by the Pukyong National University Research Foundation grant in 2002.

\section{References}

I. Pugh, S. A.; DeKook, B.; Ross, J. J. Chem. Phys. 1986, 85, 879.

2. Kawezynski, A. L.; Bar-Eli, K. J. Phys, Chem. A 1997, 101, 4592.

3. Moller, A. C. Olsen, L. F. J. Phys. Chem. B 2000, 104, 140.

4. Resch. P.; Field, R. J.; Schneider, F. W. J. Phys. Chem. 1989, 93, 2783.

5. Kim, K. R.; Lee, D. J.; Shin, K. J. J. Chem. Phys. 2002, 1/7, 2710.

6. Roux, J. C.; Vidal, C. Nonn. J. Chim, 1979, 3, 247.

7. Pacault, A.; De Kepper, P.; Hanusse, P.; Rossi, A. C. R. Acad. Sci. Paris, Ser. C 1978, 282,215.

8. De Kepper, P. Thesis, Bordeaux, 1978.

9. Boissonade, J.; De Kepper, P. J. P/ns. Chem. 1980, 84, 50 I.

10. Noyes, R. M.; Furrow, S. D. J. Am. Chem. Soc. 1982, 104, 45.

11. De Kepper, P.; Epstein, I. R. J. Am. Chem. Soc, 1982, 104, 49.

12. Furrow, S. D. J. Phys, Chem. 1987, 91, 2129.

13. Turanyi, T. React. Kinet. Catal. Lett. 1991, 45, 235.

14. Kim, K. R.; Lee, D. J.; Shin, K. J. J. Cheni. Phys. 2004, 121, 2664.

15. Kuznetsov, Y. A. CONTENT-Integrated Environnent for Anatysis of Dynamical System. Tutorial, Avallable from Institute of Mathematical Problems of Biology, Russian Academy of Sciences: Pushchno, Moscow Region I42292 Russia, 1998. 